\title{
Should Zoo Food Be Chopped for Captive Turacos?
}

\author{
Beth Griffin and James Edward Brereton * (D) \\ Zoo and Animal Science, Higher Education, University Centre Sparsholt, Westley Lane, Sparsholt, \\ Winchester SO21 2NF, UK; Beth_Griffin1995@hotmail.co.uk \\ * Correspondence: James.Brereton@sparsholt.ac.uk
}

check for

updates

Citation: Griffin, B.; Brereton, J.E. Should Zoo Food Be Chopped for Captive Turacos? Birds 2021, 2, 415-426. https://doi.org/10.3390 /birds2040031

Academic Editor: Alexandra Esther

Received: 17 October 2021

Accepted: 22 November 2021

Published: 27 November 2021

Publisher's Note: MDPI stays neutral with regard to jurisdictional claims in published maps and institutional affiliations.

Copyright: (c) 2021 by the authors. Licensee MDPI, Basel, Switzerland. This article is an open access article distributed under the terms and conditions of the Creative Commons Attribution (CC BY) license (https:/ / creativecommons.org/licenses/by/ $4.0 /)$.
Simple Summary: It is common practice for zookeepers to provide animals in their care with food that is chopped into small pieces. Some keepers suggest that chopped food reduces wastage and aggression from group-housed animals. However, there is limited evidence to support these suggestions. To investigate the effects of food condition (chopped or whole food), a study was undertaken on White-cheeked Turacos (Tauraco leucotis) and Fischer's Turacos (Tauraco fischeri) at two zoos in the United Kingdom. This study investigated the effect of food condition on turaco behaviour, the amount of food eaten, and the amount of time that keepers required to prepare the diet. Turacos ate similar amounts of food when the meals were provided in a chopped or whole format. For Fischer's Turacos, food condition significantly affected the prevalence of preening and feeding behaviour. For White-cheeked turacos, only feeding was affected by food condition. Keepers on average saved $151 \mathrm{~s}$ per meal when preparing whole-food diets. Overall, this study suggests that changing food presentation from chopped to whole did not affect food intake. Providing whole-food items may also save valuable keeper time. Future studies should investigate the impact of feeding whole-food items to more zoo animals.

Abstract: It is common practice for keepers in zoological collections to provide animals in their care with food that is chopped into small pieces. Anecdotally, it has been suggested that chopped food reduces wastage and reduces aggression from group-housed animals. However, there is limited empirical evidence to support these suggestions. To investigate the effects of food condition (chopped or whole food), a study was undertaken on White-cheeked Turacos (Tauraco leucotis) and Fischer's Turacos (Tauraco fischeri) at two zoological collections in the United Kingdom. This study investigated the effect of food condition on turaco behaviour, the amount of food eaten, and also the amount of time that keepers required to prepare the diet. There was no significant impact on the amount of food eaten as a result of providing whole food. For Fischer's Turacos, the whole-food condition significantly increased the prevalence of feeding and foraging behaviour, whilst significantly reducing preening. For White-cheeked Turacos, only feeding and foraging was affected by food condition: no other behaviours were significantly affected by chopped or whole food. Keepers on average saved 151 s per meal when preparing whole-food diets. Overall, this study suggests that changing food presentation from chopped to whole has a limited impact on food intake and behaviour. Providing whole-food items may also save valuable keeper time. Future studies should investigate the impact of feeding whole-food items to a wider range of zoo-housed species.

Keywords: chopped food; Tauraco fischeri; Tauraco leucotis; Fischer's Turaco; White-cheeked Turaco; food preparation; zoo nutrition; zookeeper time

\section{Introduction}

Despite considerable research efforts, there remain gaps in the knowledge of zoo and aquarium animal nutrition [1]. Zoological collections are faced with the challenge of not only providing food that is nutritionally comparable to the wild diet, but also encouraging animals to express naturalistic feeding behaviours. To further compound this challenge, 
many zoo-housed species have yet to be formally studied in the wild or in captivity $[2,3]$. This limits the availability of keepers and aquarists to provide the most nutritionally suitable diets for their animals.

The science of food presentation has been gathering interest recently [1]. Some food presentation techniques may provide opportunities for animals to engage in species-specific, natural behaviours, such as gnawing, carcass manipulation or plucking of food [4-6]. Careful consideration of feed presentation styles may therefore provide animals with enrichment opportunities.

One method of feeding zoo animals is to present the diet chopped into cubes [5]. Whilst frequently used in zoos globally, there is limited evidence available to suggest that animals benefit from chopped food items [7,8]. Anecdotally, it has been suggested that chopped food may limit aggression between animals and promote sharing [1]. However, behavioural research has demonstrated that providing whole-food items tended to reduce aggression $[1,7,8]$. Additionally, chopping food may increase the speed of nutrient breakdown, desiccation and bacterial contamination of food items $[5,9]$.

Research has been conducted into the effect of chopped food for a range of mammals including primates $[1,8,10]$, tapirs, and coatis (Nasua nasua) [7]. However, there is limited research available on the effect of chopped food on avian behaviour, despite the fact they are the most speciose taxon in zoological collections globally [11]. Related research on food pellet size suggests that oversized pellets improved food manipulation and gnawing behaviour in Orange-winged Parrot (Amazona amazonica) [12,13]. In preference and motivation studies, the Amazon parrots were willing to lift weights in excess of $100 \mathrm{~g}$ to gain access to over-sized pellets, even when the smaller but nutritionally identical pellets were also available [12,13]. Extensions of this research could be conducted on species that are frugivorous. Whole fruit and vegetables may therefore be valuable in promoting natural behaviours for some zoo-housed birds.

The Turacos (Family Musophagidae) are a group of 23 bird species which occur throughout Africa [14]. The majority of turaco species are specialist frugivores in the wild, with some species feeding exclusively on fruit items [15-17]. However, some turacos also supplement their diet with small amounts of leaves, flowers or galls, depending on preference and seasonal fruit availability $[18,19]$. The Great Blue Turaco (Corythaeola cristata), for example, is believed to have the highest leaf intake, with leaves making up roughly $25 \%$ of the diet [19]. In the wild, turacos are selective in terms of their fruit consumption, appearing to choose hexose-rich fruits over fruits which are high in fat or nitrogen $[18,19]$.

Hexose-rich fruits are easily digested, and turacos possess rapid food transit times as a result $[15,16]$. Studies have investigated the effects of seed size on food transit times in the gut $[15,16]$, revealing that for some species, larger seed sizes result in even faster food passage rates. Wild turacos search for food by travelling between fruiting trees and then pecking large food items or swallowing small food items whole [18]. Turacos generally forage throughout the day, and take many regular, small meals rather than one single, large meal $[19,20]$. In captivity, this means that turacos are often fed ad libitum, with constant access throughout the day to their food source.

Over 1500 Musophagidae individuals are found in zoos, according to a search of the Zoological Information Management System (ZIMS) in May 2021 [19]. While this is not a large population in comparison to other zoo-housed avian taxa, such as flamingos or penguins [19], turacos are a specialist group and are of interest to the zoo biologist. Turacos are often provided with chopped food diets in captivity, making them a good model for food presentation research.

The aim of this project was to identify whether a change in food presentation would affect the feeding behaviours of zoo-housed turacos. Additionally, this study aimed to determine the effects on keeper workload when changing from a chopped-food to wholefood diet. 


\section{Materials and Methods}

\subsection{Study Subjects}

Prior to this study commencing, this project was ethically reviewed and approved by the University Centre Sparsholt Ethical Review Committee (code TUR210919). Three groups of birds were observed for this study: two housed at Sparsholt College's Animal Management Centre (AMC) in Hampshire and one at The Living Rainforest in Berkshire. The two groups at Sparsholt College consisted of one trio of juvenile White-cheeked Turacos (Tauraco leucotis), and one adult pair of White-cheeked Turacos. Both groups were housed in aviaries with both a heated indoor and outdoor area. The exhibits were sparsely planted with small shrubs and bamboo, along with elevated perches. During the observation period for the White-cheeked Turaco groups, the temperature ranged from 3 to $13{ }^{\circ} \mathrm{C}$ and the humidity from 65 to $97 \%$. The group at the Living Rainforest were an adult pair of Fischer's Turacos (Tauraco fischeri) who were housed in a well planted aviary containing tropical plants such as a large Monstera deliciosa. The exhibit was inside a temperature-controlled (between $25-26^{\circ} \mathrm{C}$ ) and humidity-controlled (80-85\%) glass house (Figure 1). Light levels were not analysed for either group, but as the Living Rainforest exhibit was inside, light levels were generally lower. Both adult pairs included in this study were bonded male and female pairs who had been housed together for several years (Table 1). The researcher was able to differentiate between subjects by the coloured bands on their legs and by subtle differences in markings.
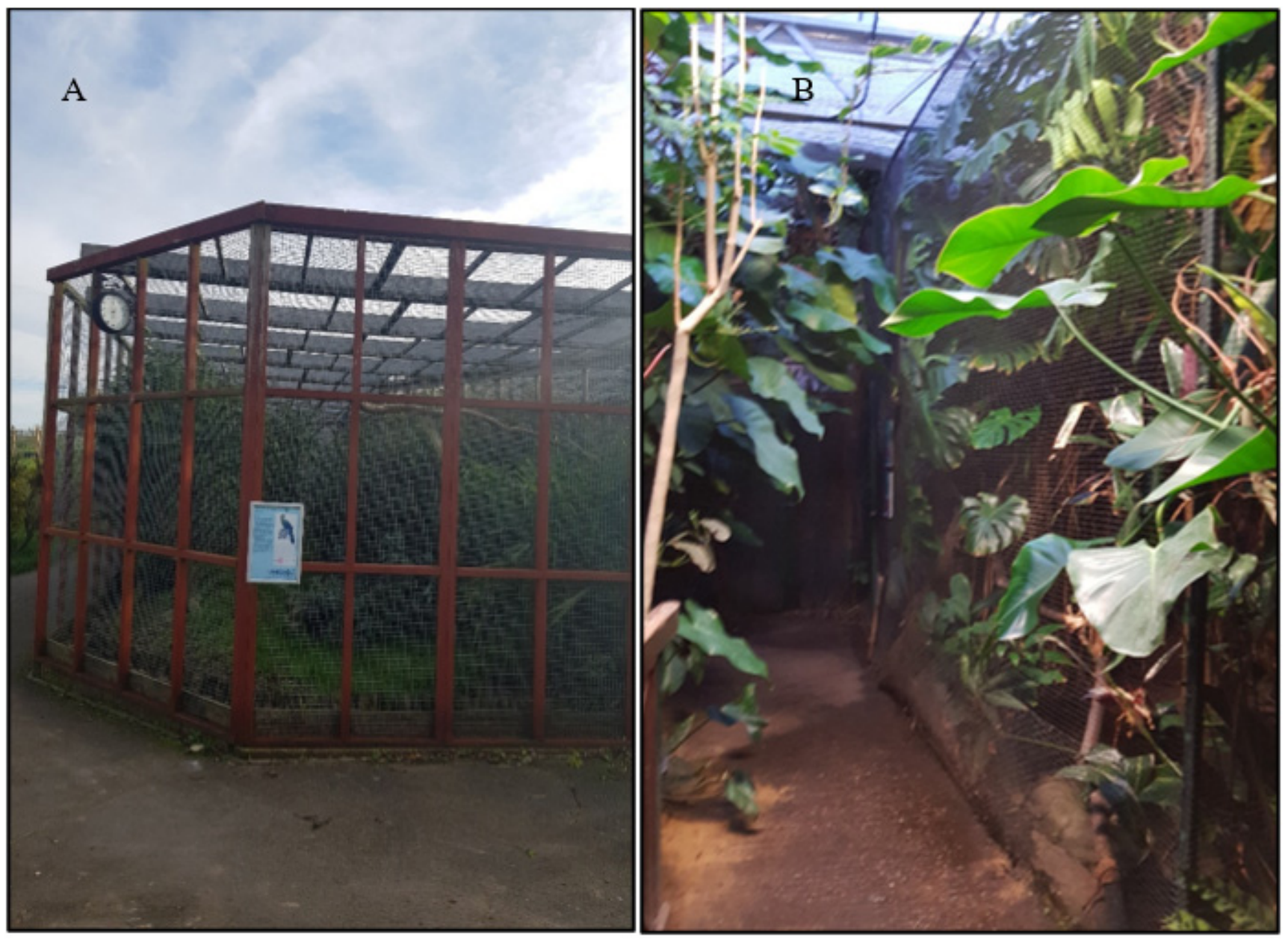

Figure 1. (A) One of the two White-cheeked Turaco aviaries at Sparsholt College and (B) Fischer's Turaco enclosure at The Living Rainforest. 
Table 1. Study subjects and locations.

\begin{tabular}{|c|c|c|c|c|}
\hline Location & Species & Sex & Life Stage & Code \\
\hline \multirow{3}{*}{ Sparsholt College Aviary 1} & \multirow{5}{*}{ White-cheeked Turaco (Tauraco leucotis) } & Unknown & \multirow{3}{*}{ Juvenile } & JW1 \\
\hline & & Unknown & & JW2 \\
\hline & & Unknown & & JW3 \\
\hline \multirow{2}{*}{ Sparsholt College Aviary 2} & & Male & \multirow{2}{*}{ Adult } & AW1 \\
\hline & & Female & & AW2 \\
\hline \multirow{2}{*}{ The Living Rainforest } & \multirow{2}{*}{ Fischer's Turaco (Tauraco fischeri). } & Male & \multirow{2}{*}{ Adult } & F1 \\
\hline & & Female & & F2 \\
\hline
\end{tabular}

Data were collected between November 2019 and January 2020 and behavioural observations were carried out from the beginning of morning feeding at 09:00-12:00 at Sparsholt College, and at morning and afternoon feeds at The Living Rainforest from 09:00 to $12: 00$ and from 14:00 to 16:00. A total of $30 \mathrm{~h}$ was collected for each group, totalling $90 \mathrm{~h}$ of observations.

\subsection{Behaviour}

All observations were conducted by the same observer (BG), who sat quietly a minimum of five meters away from the study subjects for all observations. An ethogram for state behaviours (Table 2) was created for the purpose of this study as there were no published ethograms specifically for turaco species. Some of the behaviours defined in the ethograms were adapted from work by Almeida et al. [21], Barrera et al. [22] and Blanchett [23], all of which studied a range of avian species.

Table 2. The ethogram that was used to collect data on state behaviour of turacos. Adapted from [21-23].

\begin{tabular}{ll}
\hline State Behaviours & Description \\
\hline Allo-feeding & Subject is sharing food or regurgitating to feed to another individual. \\
\hline Feeding and Foraging & $\begin{array}{l}\text { Consumption of food items. Turaco uses beak to peck or gouge food } \\
\text { items. Smaller items may be picked up in the beak and swallowed. }\end{array}$ \\
\hline Inactive & $\begin{array}{l}\text { Subject remains stationary in one position, and may be sitting, resting } \\
\text { or sleeping. }\end{array}$ \\
\hline Locomotion & $\begin{array}{l}\text { Subject is moving in a singular direction irrespective of speed via } \\
\text { running, walking or by flight. }\end{array}$ \\
\hline Perching & $\begin{array}{l}\text { Subject is sat upright or is standing in place. Active eye and head } \\
\text { movements. }\end{array}$ \\
\hline Preening & Subject uses beak and/or feet to clean own body. \\
\hline
\end{tabular}

Subject state behaviour was recorded using instantaneous focal sampling at oneminute intervals and continuous focal sampling was used for recording event behaviours. Weather conditions, temperature, and humidity were recorded using a local weather forecast, and presence of students, staff or visitors was also recorded.

\subsection{Food Intake}

In both conditions, the fruit and vegetables provided were weighed before and after the observation period to measure how much was consumed. Measurements were undertaken using an Ascher $200 \mathrm{~g}$ Portable Digital Pocket Scale: this scale allowed measurements to be measured to the closest $0.001 \mathrm{~g}$. A sample of the same foods was prepared in the same manner (chopped or whole) and was weighed before and after placement in a nearby, vacant enclosure. This extra portion acted as a correction factor, to determine 
whether excessive rain or desiccation had changed the weight of the food. When this control was analysed, the results were \pm 0.1 , so food samples were affected minimally by the environment. Quantities of food items for each group involved can be seen in Table 3. It was not possible to measure the weights of foods for Fischer's Turaco group due to accessibility issues.

Table 3. Amounts of food provided to each group of turacos at Sparsholt College and The Living Rainforest.

\begin{tabular}{llll}
\hline Feed & $\begin{array}{l}\text { Adult } \\
\text { White-Cheeked Turaco }\end{array}$ & $\begin{array}{l}\text { Juvenile } \\
\text { White-Cheeked Turaco }\end{array}$ & Fischer's Turaco \\
\hline T16 Pellet & $20 \mathrm{~g}$ & $45 \mathrm{~g}$ & $40 \mathrm{~g}$ \\
Zoo Diet A & $20 \mathrm{~g}$ & $45 \mathrm{~g}$ & - \\
Leafeater Pellet & $10 \mathrm{~g}$ & $15 \mathrm{~g}$ & - \\
(halved) & $100 \mathrm{~g}$ & $210 \mathrm{~g}$ & $200 \mathrm{~g}$ \\
Mixed Fruit & $75 \mathrm{~g}$ & - \\
Mixed Vegetables & $60 \mathrm{~g}$ & & \\
\hline
\end{tabular}

\subsection{Diet Preparation}

There were two conditions for this study: the chopped-food condition consisted of fruits and vegetables being cut up into approximately $1 \mathrm{~cm} \times 1 \mathrm{~cm}$ cubes, and in the whole-food-condition fruits and vegetables were provided either entirely whole or cut in half. The birds had previously been provided with whole fruit as enrichment (the diet was normally provided in a chopped format) and no new fruits or vegetables were used as part of this study. The conditions were provided on a randomised schedule to remove order effect. Pelleted feed was always provided in metal bowls (both groups at Sparsholt College) or in coconut bowls (The Living Rainforest) as per the normal husbandry routine. In the chopped-food condition, the fruits and vegetables were provided in a separate metal bowl to the pelleted feed. The whole foods were presented speared on nails or skewers (either hanging or attached to the walls) and were scattered throughout the enclosures. Fruit provided included apples, bananas, pears, papaya, grapes, blueberries, and plums, and the vegetables included sweet potato, broccoli, courgette, and butternut squash. Vegetables were steamed for both the chopped and whole conditions as per the standard husbandry regime. The skins of fruits were included when food was presented in the whole condition.

The amount of time required to prepare the diet was also recorded. One of the researchers $(\mathrm{BG})$ used a timer to record the number of seconds it took for keepers to prepare the diet (including weighing out pelleted feeds and washing equipment after preparation had taken place).

\subsection{Data Analysis}

Data were compiled onto an Excel ${ }^{\mathrm{TM}} 2016$ spreadsheet, and then uploaded to Minitab, version 19, for analysis. Data on 'time taken to prepare diets' were tested for normality. Data were normally distributed, and a two-sample $t$ test was run to determine whether the diet type (chopped or whole) affected the amount of time taken to prepare the diet.

The amount of food eaten was calculated by deducting the amount of food remaining at the end of each observation from the amount of food offered. A correction factor was applied to account for changes in food weight as a result of environmental conditions (rain or desiccation) (Table 1). The 'food eaten' data were not normally distributed. As a result, a Kruskal-Wallis test was used to investigate the effect of group (Fischer's, juvenile White-cheeked or adult White-cheeked) and diet condition (chopped or whole) on the amount food eaten. Pairwise post hoc tests were run; these were either Mann-Whitney $\mathrm{U}$ tests (when comparing between adults and juveniles) or Wilcoxon tests (comparing between chopped and whole conditions).

To consider the differences between species and housing conditions, behavioural data for Fischer's Turaco and White-cheeked Turaco were analysed separately. For Fischer's Tu- 
raco, the effect of chopped or whole-food condition on behaviour was analysed using either paired $t$ tests or Wilcoxon's tests, depending on whether data were normally distributed. For the White-cheeked Turaco, the effects of food condition and social group were analysed using a series of Friedman's ANOVAs, as all data were determined to be non-parametric. Where significant differences were identified, pairwise post hoc Wilcoxon's tests were run to determine where significant differences lay.

\section{Results}

\subsection{Behaviour}

Activity budgets were produced to illustrate the differences in behaviour between food conditions and groups (Figures 2 and 3). For Fischer's Turacos, the whole-food condition significantly increased the amount of feeding and foraging, and decreased the amount of preening observed (Table 4). For the White-cheeked Turacos, the whole-food condition significantly increased allo-feeding and preening. Post hoc Wilcoxon tests revealed that for both preening and allo-feeding, the adult chopped and whole conditions were significantly different to the juvenile chopped and whole conditions; juveniles spent more time feeding and less time preening than adults. Juveniles also increased the amount of time spent feeding when given whole foods.

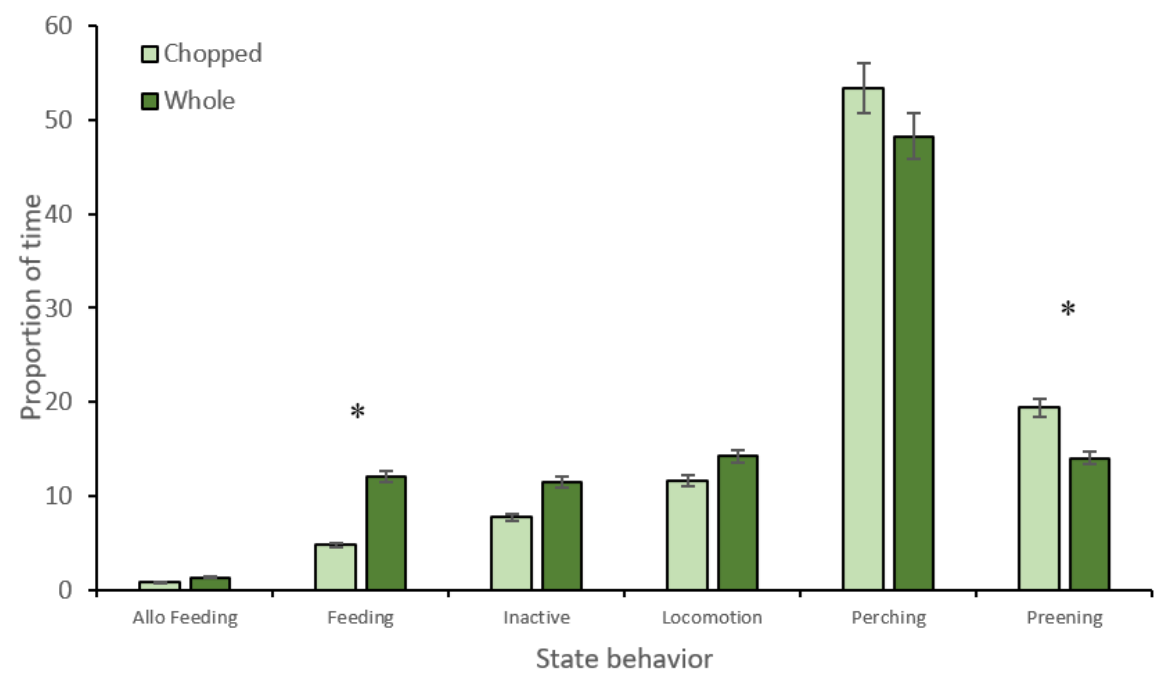

Figure 2. Activity budget for Fischer's Turaco when provided with either chopped or whole-food items $\left(+/-\right.$ standard error). ${ }^{*}$ indicates a significant difference $(p<0.05)$.

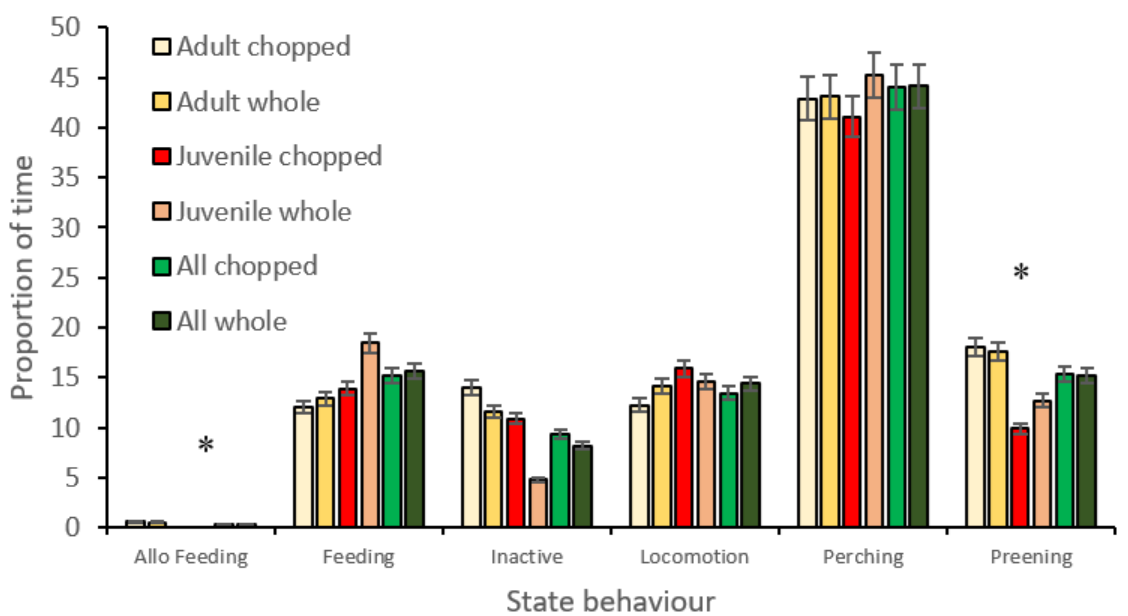

Figure 3. Activity budget for the adult, juvenile and all (adult and juvenile combined) White-cheeked Turacos when provided with either chopped or whole-food items (+/ - standard error). * indicates a significant difference $(p<0.05)$. 
Table 4. Test outputs for comparisons of chopped and whole-food conditions. ${ }^{*}$ indicates significant values $(p<0.05)$.

\begin{tabular}{|c|c|c|c|c|}
\hline Species & Behaviour & Test & Test Statistic & $p$ \\
\hline \multirow{7}{*}{ White-cheeked Turaco } & Allo-feeding & Friedman's ANOVA & $X^{2}(3)=20.26$ & $<0.001 *$ \\
\hline & Feeding and foraging & Friedman's ANOVA & $X^{2}(3)=3.33$ & 0.288 \\
\hline & Inactive & Friedman's ANOVA & $X^{2}(3)=6.85$ & 0.077 \\
\hline & Locomotion & Friedman's ANOVA & $X^{2}(3)=5.63$ & 0.566 \\
\hline & Perching & Friedman's ANOVA & $X^{2}(3)=1.33$ & 0.717 \\
\hline & Preening & Friedman's ANOVA & $X^{2}(3)=18.13$ & $<0.001 *$ \\
\hline & Allo-feeding & Wilcoxon & $Z(18)=20$ & 0.539 \\
\hline \multirow{5}{*}{ Fischer's Turaco } & Feeding and foraging & Wilcoxon & $Z(18)=26.12$ & $0.001 *$ \\
\hline & Inactive & Wilcoxon & $Z(18)=122.5$ & 0.113 \\
\hline & Locomotion & Paired $t$ test & $t(57)=-1.47$ & 0.146 \\
\hline & Perching & Paired $t$ test & $t(57)=1.77$ & 0.08 \\
\hline & Preening & Wilcoxon & $Z(18)=365.5$ & $0.006^{*}$ \\
\hline
\end{tabular}

\subsection{Food Intake}

Comparisons were made between the amount of food eaten by the adult and juvenile White-cheeked Turacos under the chopped and whole conditions (Figure 4). A Kruskal-Wallis test revealed this finding to be significant $(\mathrm{H}=14.29, p<0.001)$. Post hoc Mann-Whitney U (between adult and juvenile White-cheeked Turacos) and Wilcoxon tests (between food conditions) were run (Table 5). The significant differences occurred between the adult and juvenile groups, but not between the condition (chopped versus whole). Specific weights of foods and correction factors can be found in Table A1.

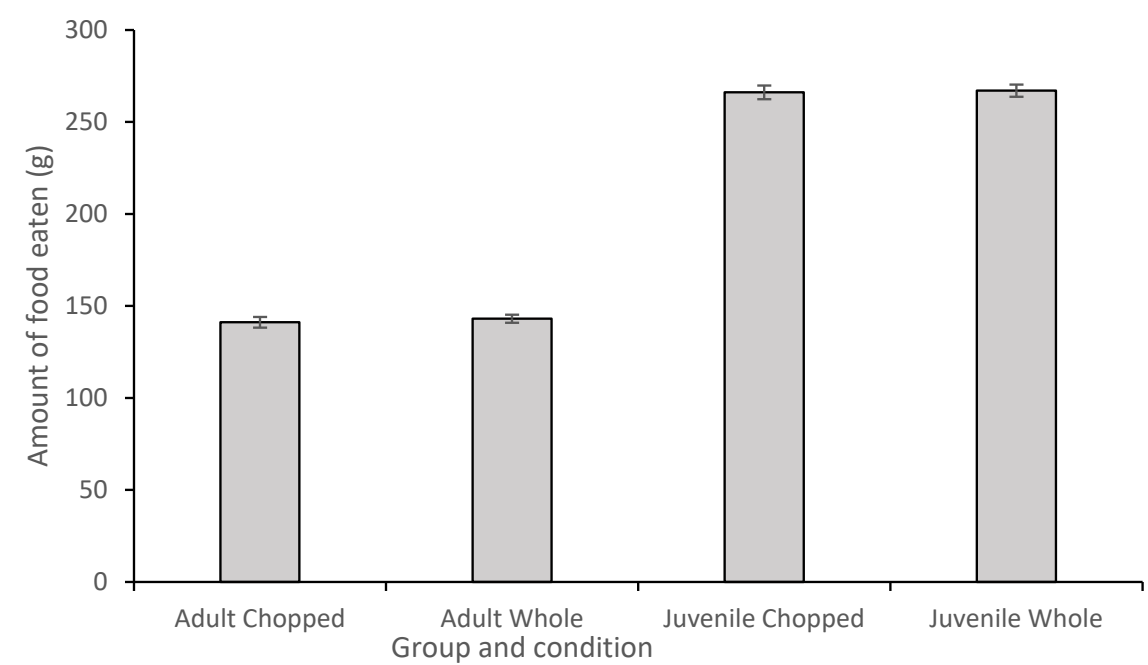

Figure 4. Average amount of food eaten by the adult and juvenile White-cheeked Turacos, +/standard error.

\subsection{Diet Preparation}

There was a significant difference between the amount of time keepers took to prepare diets containing chopped and whole food $(t=0.546, \mathrm{df}=17, p<0.001)$. On average, keepers saved $151 \mathrm{~s}$ of time per meal when preparing whole food (Figure 5). 
Table 5. Pairwise comparisons between the amount of food eaten by adult and juvenile birds under chopped and whole-food conditions. Significant values are indicated by an asterisk.

\begin{tabular}{lllll}
\hline Group & Group & Difference & Test Statistic & $p$ \\
\hline \multirow{2}{*}{ Adult chopped } & Adult whole & -1.522 & $\mathrm{~N}=5, \mathrm{~W}=5$ & 0.295 \\
\cline { 2 - 5 } & Juvenile chopped & -125.036 & $\mathrm{~W}=15$ & $0.015^{*}$ \\
\cline { 2 - 5 } & Juvenile whole & -125.579 & $\mathrm{~W}=15$ & $0.012^{*}$ \\
\hline \multirow{2}{*}{ Adult whole } & Juvenile chopped & -123.233 & $\mathrm{~W}=15$ & $0.012^{*}$ \\
\cline { 2 - 5 } & Juvenile whole & 123.257 & $\mathrm{~W}=40$ & $0.012 *$ \\
\hline Juvenile chopped & Juvenile whole & -1.311 & $\mathrm{~N}=5, \mathrm{~W}=5$ & 0.295 \\
\hline
\end{tabular}

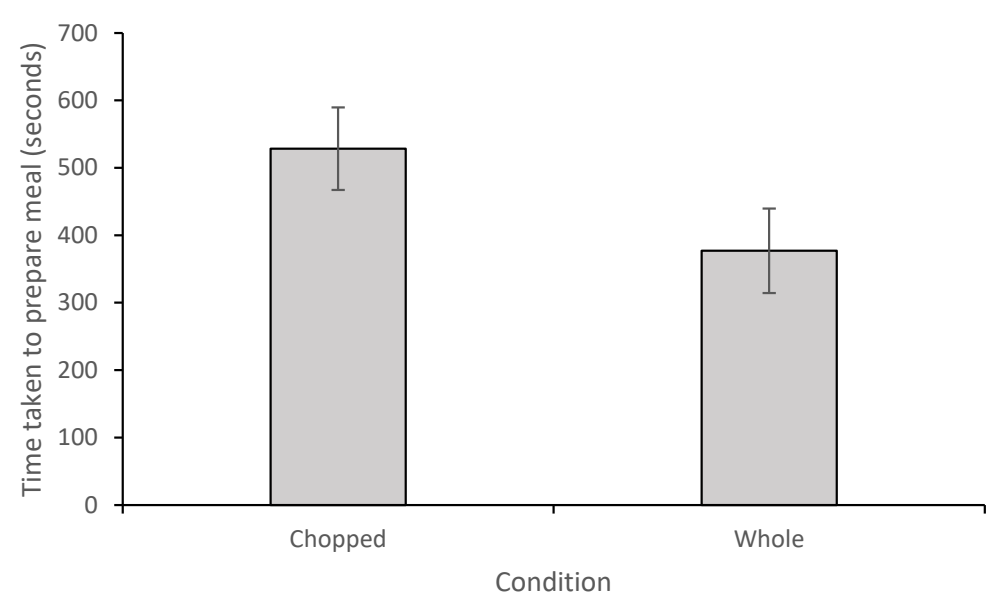

Figure 5. Time taken to prepare meals and wash equipment for the diet prepared in a chopped or whole format.

\section{Discussion}

Overall, there was no significant difference between the amount eaten for turacos under either the chopped or whole-food conditions: significant differences were found only in the amount of food eaten by juveniles versus adult birds. Food condition significantly affected the amount of preening and feeding seen in Fischer's turacos, and no behaviours in White-cheeked Turacos. Keepers spent significantly less time preparing diets that contained whole fruits and vegetables, thus saving time for other duties.

\subsection{Behaviour}

Two behaviours were significantly affected by food condition for Fischer's turacos: these were food manipulation, feeding and preening. Preening behaviour decreased when whole foods were provided, whereas feeding increased. The reduction in preening behaviour may be as a result of increased feeding: birds required more time to process food, so had less time to engage in preening. Locomotion, whilst not significant, also increased slightly for Fischer's turaco pair when whole foods were provided.

For the White-cheeked Turacos, the results are more complex. While two results (allo-feeding and preening) were significant, post hoc analysis revealed that the significant differences were between adult and juvenile pairs for preening, with adults spending more time preening. Allo-feeding occurred in adults but not in juveniles: this is because allo-feeding is related to pair-bonding [19]. The change in preening behaviour is also attributable to differences between adult birds and juveniles. Additionally, there were differences in feeding between juveniles and adults in response to the whole-food condition. While the trend toward increased time spent feeding was seen for all birds with whole foods, the juvenile turacos appeared to increase their time spent feeding more than adults. This is important to note, because it suggests that birds of particular life stages may be 
more sensitive to food condition changes. It is therefore important to monitor all bird life stages, rather than focus solely on adults [22,23].

Across both species, the amount of time spent feeding increased when whole foods were provided. The whole-food items may have required more time to process and therefore presented a greater challenge than the traditional diet. Wild turacos feed on a variety of different fruit species $[15,18,19]$, encompassing a range of different sizes and textures. Some of the fruits encountered in the wild are similar in size to chopped food items. For both wild and captive turacos, these food items were generally swallowed whole. In this study, the larger food items required turacos to peck at the food and gouge out portions of fruit using their beaks. This required the turacos to expend a little more energy in the processing of their food and is reflective of some of the larger fruit items that may be encountered in their African forest habitat [18]. In this study, relatively soft fruits were used: some wild fruits may have much tougher skins and rinds that require further processing [19].

Food interaction times have increased in other zoo studies when foods are provided whole (e.g., in tapirs and macaques [1]). In Amazon parrots, preference has also been seen for larger food items, even when both large and small items are of the same nutritional value $[12,13]$. This extended period of time engaging in food manipulation and feeding may have some enrichment value for the birds [24,25]. An increase in these behaviours may also have some benefit for public engagement in a zoo environment, as increased animal activity has been shown to have a significant bearing on visitor interest [26].

Inactivity was not affected by food condition. The differences in inactivity level appeared to be much greater between individuals than as a result of food condition. Increased activity levels are often considered beneficial for zoo animals, particularly for species that become inactive in captivity. It is not clear that food presentation style affected the inactivity levels of the birds. If the aim is to increase activity levels, the change of a predominantly whole-food diet may not satisfy this aim [26,27].

Overall, the feeding of whole-food items had relatively little influence on behaviour, aside from feeding behaviour. From one perspective, this suggests that the food condition has limited impact on the behaviour and welfare of the birds. Many birds are neophobic when changes are made to their diets [21], so it is promising to note that the birds did not show clear signs of aggression or distress when whole-food items were provided. If birds showed few behavioural responses to the change in feeding style, it is likely that the food condition did not impact bird welfare.

\subsection{Food Intake}

There was no impact of food presentation style on feed intake. Whilst significant differences were identified, these were between groups (juvenile versus adult Whitecheeked Turaco) rather than between feeding styles. Generally, juvenile birds tended to take in more food than the adults, which may be in keeping with higher nutrient requirements for growing birds. Despite the difference in intake between groups, there were not significant difference as a result of diet. This means that the whole food style did not cause birds to overfeed or stop feeding on their fruit. This is important to note because turacos are often also fed a pelleted component in their diets (in this study, T16, leafeater pellets and Zoo Diet A). These pelleted feeds contain much of the vitamin and mineral diet that the birds require for good health. While pellet intake was not directly assessed in this study, it should be noted that food condition change did not appear to affect the quantity of fruit taken, and therefore should not affect the normal amount of pellet eaten per bird.

Feed intake studies are an important tool for assessing the effects of dietary change [25]: while the diet was strictly speaking not changed, the presentation style was. A sudden decrease in diet may be a sign of either neophobia or unsuitable diet: this was not identified in this study. If the amount of food eaten did not change between conditions, this suggests there was limited impact of diet style on the accessibility of food to the turacos. 


\subsection{Diet Preparation}

Overall, keepers were able to save an average of $151 \mathrm{~s}$ of time when preparing wholefood diets. Some of this time was saved because the keepers were not chopping foods: the remainder was saved because keepers were spending less time washing knives and chopping boards. Whilst $151 \mathrm{~s}$ initially does not appear to be much time, it should be noted that $2.5 \mathrm{~min}$ on average could be saved at every feeding time. For a single turaco exhibit, the total time saved per year using whole food preparation is $15.31 \mathrm{~h}$. This time saving might be multiplied by the number of aviaries containing frugivorous species that could be provided with whole-food diets. The extra time saved might then be devoted to other keeper duties: for example, keepers may be able to spend more time engaged in enrichment activities [5].

Additionally, there may be some benefits in leaving foods in a whole condition in terms of nutritional quality. It is well recognised in human nutrition studies that chopping of foods increases their metabolic rate, desiccation rate, browning and production of waste products such as ethylene $[28,29]$. The higher the environmental temperature and the smaller the fruit and vegetable pieces, the more rapidly changes in nutritional quality occur [9]. In exhibits where temperatures remain high (such as rainforest biomes), the effects of chopping impact food quality more rapidly. This may result in food that loses some of its vitamin and nutritional value or tastes unpalatable to the birds. Additionally, cut surfaces are more likely to result in bacterial contamination from food preparation utensils or enclosure furnishings [24]. Maintaining food in a whole format may therefore result in food staying fresh for longer periods of time.

\subsection{Future Directions}

There is a growing evidence base that suggests naturalistic feeding styles may be beneficial for welfare $[1,5,7]$. However, the literature on food presentation, specifically on the chopped versus whole concept, tends to focus on mammal species [5], even though birds are better represented in zoological collections in terms of numbers of species [11]. There remain many gaps to be filled in the literature on bird food presentation [25]. Model species for chopped and whole food presentation research should be species that feed primarily on fruits and vegetables in captivity. Among the birds, the Orders Columbiformes (pigeons and doves), Bucerotiformes (hornbills), Psittaciformes (parrots) and some Passeriformes (songbirds) are good candidates for future study, on account of their diets and representation in captivity [30]. Research should be undertaken whenever trialling the new feeding style to ensure that food intake and behaviour are not impacted.

Future research should also investigate the ability of birds to process thick peels or shelled fruits and vegetables. In this study, the fruits that were used had thin skins and were easy to gouge. The vegetables used were also steamed in order to make the food softer. As a result, it is beyond the scope of this study to determine whether turacos could process fruits with thicker skins, such as pineapples [17]. It is likely that some birds, such as macaws, may be better equipped to process tough fruits: the blue-and-yellow macaw is an example [21,31]. Future research could determine the thickness and strength of fruit peels, shells and rinds and use this information to identify a bird's capabilities in terms of food manipulation. Future studies should continue to incorporate control food to account for water accumulation or loss through evaporation.

Previous studies on zoo-housed birds have also showed that other variables, such as temperature, humidity, visitor and keeper presence may affect behaviour [30]. The potential impact of these extraneous variables was not controlled for in this study. Similarly, it should be acknowledged that there only a small sample size was available for this study. While this small sample size is reflective of the nature of turaco keeping (they are often kept in pairs or singly), future studies should aim to overcome this small sample challenge. To summarise, future multi-zoo studies could take into account the influence of environmental and anthropocentric variables, ensuring they maximise the sample used in their study. 


\section{Conclusions}

The provision of whole fruits and vegetables in the diet of turacos resulted in limited behavioural change, with birds slightly more time engaged in feeding and food manipulation. Whilst the behavioural impact is limited, whole-food items provide a much more naturalistic feeding method, providing animals with a captive environment that matches their wild habitat a more closely. Food condition also had no effect on food intake, suggesting that the birds were not avoiding the feeding style. This suggests that there was minimal welfare impact associated with the whole feeding condition. Keepers were also able to save a significant amount of time when preparing whole-food diets. Given these findings, whole-food diets could be applied to a wider range of frugivorous birds in captivity, provided that food intake and behavioural effects are assessed before the diet is rolled out fully. The mainstreaming of whole-food items in avian husbandry could provide opportunities for birds to engage in natural behaviours such as gnawing, peeling and food manipulation, whilst also freeing more time for keepers to focus on other tasks such as preparation of enrichment.

Author Contributions: This project was conceptualised and supervised by J.E.B. Data collection was conducted by B.G. These data were analysed and the manuscript was written by J.E.B. and edited by B.G. All authors have read and agreed to the published version of the manuscript.

Funding: This research received no external funding.

Institutional Review Board Statement: The study was conducted according to the guidelines of the Declaration of Helsinki, and approved by Ethics committee of University Centre Sparsholt (protocol code TUR210919 and date of approval 21/0/2019).

Informed Consent Statement: Not applicable.

Data Availability Statement: The data presented in this study are available on request from the corresponding author. The data are not publicly available due to privacy of zoo records.

Acknowledgments: The authors would like to thank the keepers at Sparsholt's Animal Management Centre, and the keepers at the Living Rainforest. Particular thanks go to Gary Miller and Tina Bouttle for guidance and correspondence.

Conflicts of Interest: The authors declare no conflict of interest.

\section{Appendix A}

Table A1. Table of food weights (including dummy food) and correction factors used to take into account evaporation and humidity.

\begin{tabular}{|c|c|c|c|c|c|c|c|c|}
\hline Group & $\begin{array}{l}\text { Food } \\
\text { Presentation }\end{array}$ & $\begin{array}{l}\text { Food Weight } \\
\text { in }(\mathrm{g})\end{array}$ & $\begin{array}{l}\text { Food Weight } \\
\text { out (g) }\end{array}$ & $\begin{array}{l}\text { Amount } \\
\text { Eaten (g) }\end{array}$ & $\begin{array}{l}\text { Food Weight in } \\
\text { (Dummy Food) } \\
\text { (g) }\end{array}$ & $\begin{array}{l}\text { Food Weight out } \\
\text { (Dummy Food) } \\
\text { (g) }\end{array}$ & $\begin{array}{l}\text { Correction } \\
\text { Factor }\end{array}$ & $\begin{array}{l}\text { Corrected } \\
\text { Meal (g) }\end{array}$ \\
\hline Adult & Chopped & 158.97 & 21.73 & 137.24 & 160.56 & 160.55 & 1.00 & 137.23 \\
\hline Adult & Chopped & 159.57 & 18.65 & 140.92 & 160.56 & 160.53 & 1.00 & 140.89 \\
\hline Adult & Chopped & 160.43 & 20.84 & 139.59 & 160.03 & 160.04 & 1.00 & 139.60 \\
\hline Adult & Chopped & 160.45 & 16.26 & 144.19 & 158.98 & 158.91 & 1.00 & 144.13 \\
\hline Adult & Chopped & 161.12 & 17.25 & 143.87 & 161.11 & 161.09 & 1.00 & 143.85 \\
\hline Juvenile & Chopped & 284.02 & 13.21 & 270.81 & 284.58 & 284.51 & 1.00 & 270.74 \\
\hline Juvenile & Chopped & 284.72 & 22.74 & 261.98 & 284.71 & 284.71 & 1.00 & 261.98 \\
\hline Juvenile & Chopped & 284.77 & 21.67 & 263.10 & 285.57 & 285.52 & 1.00 & 263.05 \\
\hline Juvenile & Chopped & 284.98 & 19.06 & 265.92 & 285.22 & 285.23 & 1.00 & 265.93 \\
\hline Juvenile & Chopped & 285.33 & 16.35 & 268.98 & 285.67 & 285.64 & 1.00 & 268.95 \\
\hline Adult & Whole & 159.49 & 13.78 & 145.71 & 158.23 & 158.24 & 1.00 & 145.72 \\
\hline Adult & Whole & 159.69 & 17.39 & 142.30 & 160.41 & 160.39 & 1.00 & 142.28 \\
\hline Adult & Whole & 160.03 & 15.14 & 144.89 & 159.78 & 159.82 & 1.00 & 144.93 \\
\hline Adult & Whole & 161.16 & 19.30 & 141.86 & 159.99 & 159.97 & 1.00 & 141.84 \\
\hline Adult & Whole & 161.37 & 20.75 & 140.62 & 160.63 & 160.67 & 1.00 & 140.66 \\
\hline Juvenile & Whole & 284.34 & 19.37 & 264.97 & 284.68 & 284.71 & 1.00 & 265.00 \\
\hline Juvenile & Whole & 284.46 & 17.94 & 266.52 & 284.24 & 284.19 & 1.00 & 266.47 \\
\hline Juvenile & Whole & 285.48 & 21.55 & 263.93 & 285.66 & 285.64 & 1.00 & 263.91 \\
\hline Juvenile & Whole & 285.61 & 18.36 & 267.25 & 284.97 & 284.96 & 1.00 & 267.24 \\
\hline
\end{tabular}




\section{References}

1. Plowman, A.; Green, K.; Taylor, L. Should zoo food be chopped? Zoo Anim. Nutr. 2009, 4, $193-201$.

2. Melfi, V. There are big gaps in our knowledge, and thus approach, to zoo animal welfare: A case for evidence-based zoo animal management. Zoo Biol. 2009, 28, 574-588. [CrossRef] [PubMed]

3. Rose, P.E.; Brereton, J.E.; Rowden, L.J.; de Figueiredo, R.L.; Riley, L.M. What's new from the zoo? An analysis of ten years of zoo-themed research output. Palgrave Commun. 2019, 5, 128. [CrossRef]

4. Regaiolli, B.; Angelosante, C.; Marliani, G.; Accorsi, P.A.; Vaglio, S.; Spiezio, C. Gum feeder as environmental enrichment for zoo marmosets and tamarins. Zoo Biol. 2020, 39, 73-82. [CrossRef]

5. Brereton, J.E. Challenges and Directions in Zoo and Aquarium Food Presentation Research: A Review. J. Zool. Bot. Gard. 2020, 1, 13-23. [CrossRef]

6. McPhee, M.E. Intact carcasses as enrichment for large felids: Effects on on-and off-exhibit behaviors. Zoo Biol. 2002, 21, 37-47. [CrossRef]

7. Shora, J.A.; Myhill, M.G.N.; Brereton, J.E. Should zoo foods be coati chopped? J. Zoo Aquar. Res. 2018, 6, 22-25.

8. Smith, A.; Lindburg, G.; Vehrencamp, S. Effect of food preparation on feeding behaviour of lion-tailed macaques. Zoo Biol. 1989, 8, 57-65. [CrossRef]

9. Rico, D.; Martin-Diana, A.B.; Barat, J.M.; Barry-Ryan, C. Extending and measuring the quality of fresh-cut fruit and vegetables: A review. Trends Food Sci. Tech. 2007, 18, 373-386. [CrossRef]

10. Mathy, J.W.; Isbell, L.A. The relative importance of size of food and interfood distance in eliciting aggression in captive rhesus macaques (Macaca mulatta). Folia Primatol. 2001, 72, 268-277. [CrossRef] [PubMed]

11. Brereton, S.R.; Brereton, J.E. Sixty years of collection planning: What species do zoos and aquariums keep? Int. Zoo Yearb. 2020, 54, 131-145. [CrossRef]

12. Rozek, J.; Danner, L.; Stucky, P.; Millam, J. Over-sized pellets naturalize foraging time of captive Orange-winged Amazon parrots (Amazona amazonica). Appl. Anim. Behav. Sci. 2010, 125, 80-87. [CrossRef]

13. Meehan, C.; Garner, J.; Mench, J. Environmental enrichment and development of cage stereotypy in Orange-winged Amazon parrots (Amazona amazonica). Devel. Psychobiol. 2014, 44, 209-218. [CrossRef]

14. Tuinen, P.V.; Valentine, M. Phylogenetic relationships of turacos (Musophagidae; Cuculiformes) based on comparative chromosome banding analysis. Ibis 1986, 128, 364-381. [CrossRef]

15. Wilson, A.L.; Downs, C.T. The effect of seed packaging on digestion and food preference by Purple-crested (Gallirex porphyreolophus) and Knysna (Tauraco corythaix) Turacos. J. Ornithol. 2011, 152, 193-200. [CrossRef]

16. Wilson, A.L.; Downs, C.T. Food intake rates, assimilation efficiency, and transit times of Knysna (Tauraco corythaix) Turacos fed South African indigenous fruit. J. Ornithol. 2012, 153, 285-290. [CrossRef]

17. Hulbert, A.J.; Hunt, K.A.; Rose, P.E. A multi-zoo investigation of nutrient provision for captive red-crested turacos. Zoo Biol. 2017, 36, 152-160. [CrossRef]

18. Sun, C.; Moermond, T.C.; Givnish, T.J. Nutritional determinants of diet in three turacos in a tropical montane forest. Auk 1997, 114, 200-211. [CrossRef]

19. Sun, C.; Moermond, T.C. Foraging ecology of three sympatric turacos in a montane forest in Rwanda. Auk 1997, 114, 396-404. [CrossRef]

20. Species360. Zoological Information Management System. Available online: https:/ / zims.species360.org/ (accessed on 26 May 2021).

21. Almeida, A.; Palme, R.; Moreira, N. How environmental enrichment affects behavioural and glucocorticoid responses in captive blue-and-yellow macaws (Ara ararauna). Appl. Anim. Behav. Sci. 2018, 201, 125-135. [CrossRef]

22. Barrera, J.; Chong, L.; Judy, K.; Blumstein, D. Reliability of public information: Predators provide more information about risk than conspecifics. Anim. Behav. 2011, 81, 779-787. [CrossRef]

23. Blanchett, M. Investigating the Use of GIS for Monitoring Visitor Effects and Enclosure Use of Captive Birds in a Mixed Species, Free-Ranging Aviary at Lowry Park Zoo, Tampa FL. 2018. Available online: http:/ / atrium.lib.uoguelph.ca/xmlui/bitstream/ handle/10214/12133/Blanchett_Mackenzie_201801_Msc.pdf?sequence=5\&isAllowed=y (accessed on 20 February 2020).

24. Nguyen-the, C.; Carlin, F. The microbiology of minimally processed fresh fruits and vegetables. Crit. Rev. Food Sci. Nutrit. 1994, 34, 371-401. [CrossRef] [PubMed]

25. Fidgett, A.L.; Gardner, L. Advancing avian nutrition through best feeding practice. Int. Zoo Yearb. 2014, 48, 116-127. [CrossRef]

26. Moss, A.; Esson, M. Visitor interest in zoo animals and the implications for collection planning and zoo education programmes. Zoo Biol. 2010, 29, 715-731. [CrossRef] [PubMed]

27. Field, D.; Thomas, R. Environmental enrichment for psittacines at Edinburgh Zoo. Int. Zoo Yearb. 2000, 37, 232-237. [CrossRef]

28. Cocci, E.; Rocculi, P.; Romani, S.; Rosa, M.D. Changes in nutritional properties of minimally processed apples during storage. Postharvest Biol. Tech. 2006, 39, 265-271. [CrossRef]

29. Shewfelt, R.L. Quality of minimally processed fruits and vegetables. J. Food Qual. 1987, 10, 143-156. [CrossRef]

30. Rose, P.E.; Scales, J.S.; Brereton, J.E. Why the "Visitor Effect" Is Complicated. Unraveling Individual Animal, Visitor Number, and Climatic Influences on Behavior, Space Use and Interactions With Keepers-A Case Study on Captive Hornbills. Front. Vet Sci. 2020, 7, 236. [CrossRef]

31. James, C.W.; Nicholls, A.J.; Freeman, M.S.; Hunt, K.A.; Brereton, J.E. Should zoo food be chopped: Macaws for consideration. J. Zoo Aquar. Res. 2021, 9, 200-207. 